УдК 655.3.022.11

\title{
ОБРОБКА МЕТАЛІЗОВАНИХ КОЛОЇДНИХ СИСТЕМ
}

( А. С. Морозов, к.т.н., доцент, М. В. Івасенко, О. В. Шаховая, студентки, НТУУ “КПІ», Київ, Україна

Рассмотрены аспекты движения металлических частиц в вязких средах (полиграфические краски), а также предложена физическая модель поведения таких частиц при активированной обработке.

Aspects of motion metallic particles into viscous mediums (printing paints) and was proposed physical model of the treatment such particles at the activated processing are considered.

\section{Постановка проблеми}

Одним з найважливіших чинників стабілізації $€$ гідродинамічний опір витісненню рідкого дисперсійного середовища 3 прошарку між частинками, що зближуються. Враховуючи його неоднорідність (гетерогенність), досить складно спрогнозувати вплив в'язкісних властивостей на таку гідродинамічну характеристику. Непрямою характеристикою кінетичної стійкості металізованої фарби як колоїдної системи є її схильність до седиментації.

На початку полімеризації рідка металізована система поступово перетворюється на гель і частково втрачає агрегатну стійкість, але зберігає кінетичну або тимчасову седиментаційну. Вплив сил на седиментаційну стійкість системи залежить від кількості та дисперсності частинок металевого наповнювача. Седиментаційна стійкість металізованої колоїдної системи пов'язана опосередковано 3 умовами для активації такої системи зовнішніми коливаннями. Тому виникає актуальна задача аналізу прогнозованої поведінки металевих частинок при акустичній обробці дисперсійного середовища.

\section{Мета роботи}

Представлене наукове дослідження має на меті обґрунтувати механізм акустичного очищення металевих частинок у колоїдних системах поліграфічного призначення.

\section{Результати проведених досліджень}

Відомо, що при відносно великих відстанях (30..50 мкм) між компонентами дисперсної фази, зближення частинок відбувається за рахунок інерційних, гравітаційних сил; при зменшенні відстані проявляються молекулярні сили взаємодії [1-3]. Рух частинок наповнювача у бідисперсній системі (якою є металізована колоїдна) визначається в основному дією інерційних сил, які виникають на початку викривлення ліній потоку рідини, що обтікає поверхню дисперсних частинок. За даними сучасних досліджень, 
при відстані 10...20 мкм між ними, седиментації починає перешкоджати гідродинамічна взаємодія, зумовлена в'язким опором шарів рідини. Однак, при таких відстанях частинки можуть зближатися завдяки дії гідродинамічної сили, яка не може забезпечити безпосередній контакт між компонентами внаслідок зростаючого опору прошарків дисперсної фази.

При введенні у композицію дрібнодисперсного електромагнітного наповнювача виникає сила магнітної взаємодії, яка створюючи електромагнітний бар'єр, сприяє рівномірному розподілу магнітного наповнювача в об'ємі композиції [4]. Отже, сумарна сила, що діє на дисперсну частинку, яка наближається у процесі седиментації до задрукованої поверхні, в загальному випадку дорівнює:

$$
\mathrm{F}=\mathrm{F}_{\mathrm{t}}+\mathrm{F}_{\mathrm{m}}+\mathrm{F}_{\mathrm{u}}+\mathrm{F}_{\mathrm{e}}
$$

де $F_{t}$ - сила тяжіння малої частинки; $\mathrm{F}_{\mathrm{m}}$ - сила міжмолекулярної взаємодії, $F_{\mathrm{u}}$ - сила гідродинамічної взаємодії, $\mathrm{F}_{\mathrm{e}}$ сила електромагнітної взаємодії.

При формуванні каркасу просторової сітки наповнювача, в прошарках якої розміщується полімерна матриця, обробка наповнених полімерних композицій електромагнітним полем дозволяє підвищити агрегативну та седиментаційну стійкість систем і отримати захисні полімеркомпозиційні покриття 3 достатньо рівномірним розподілом наповнювача.

у процесі седиментації і заповнення (у випадку несплива- ючих пігментів) впадин мікронерівностей матеріалу з нанесеною друкарською фарбою дрібні частинки, у тому числі й металеві, утворюють коагулянти, площа контакту яких із поверхнею перехідного шару задруковуваного матеріалу перевищує площу контакту початкових частинок. Коагулянти формуються 3 дрібних фракцій порошку на мікронерівностях поверхні достатньо щільної підкладки, які забезпечують адгезійну стійкість покриття за рахунок ван-дер ваальсівської взаємодії [4].

Поліграфічне покриття у більшості випадків є фарбовою плівкою на основі наповнених полімерів, структура яких була обумовлена поступовим перетворенням рідкоподібного в'яжучого у тверду композиційну сполуку [5]. Кінетика цього перетворення визначається гамою фізико-хімічних показників: швидкістю всотування і випаровування розчинника; градієнтом його концентрації у локальних поверхневих зонах задруковуваних матеріалів; присутністю сторонніх включень у вигляді мікрокрапель води та інших домішок.

На активацію металізованих колоїдних розчинів ультразвуковими коливаннями в реальних умовах та швидкість укрупнення і осадження частинок, завислих у рідкому середовищі, впливають інтенсивність та час ультразвукового впливу, а також параметри оброблюваного технологічного об'єму. Для досягнення максимально можливої інтенсивності процесу коагуляції частинок в процесі ультра- 
звукової обробки металізованого колоїдного розчину необхідно оптимізувати інтенсивність або час ультразвукового впливу.

Металізовані колоїдні розчини поліграфічного призначення можуть бути використані як модельні системи для виявлення закономірностей впливу полімерів на тверду поверхню. Виникає необхідність в проведенні досліджень, скерованих на виявлення оптимальних режимів ультразвукового впливу при умові досягнення максимальної стабілізації і гомогенізації металізованих колоїдних розчинів шляхом одночасного подрібнення крупних пластифікованих гранул на більш дрібні та коагуляції у відносно рівноважну дисперсну фазу у вигляді полімерофільних кулькоподібних частинок.

Механізм акустичної коагуляції пов'язують з дією на частинки сил гідродинамічної природи - сили Бернуллі та сили Б'єркнеса. Проте вирази для цих сил отримані для випадку гідродинамічної дії частинок в однорідному стаціонарному потоці ідеальної нестисливої рідини, у той же час, як при поширенні звукової хвилі течія рідини суттєво неоднорідна і нестаціонарна.

При вивченні гідродинамічної взаємодії частинок у рідині можливі різні постановки задачі. Це пов'язано 3 можливими спрощеннями рівнянь гідродинаміки, які $\epsilon$ нелінійними в частині змінних величин. В літературі достатньо багато праць, присвячених задачі по взаємодії частинок у потоці в'язкої нестисливої рідини при малих числах Рейнольдса [6-9]. Рівняння руху рідини при цьому суттєво спрощуються і стають лінійними рівняннями Стокса. При великих частотах нестаціонарні доданки в рівняннях руху стають основними.

Відомо, що розподілення швидкості тиску навколо двох частинок однакового радіусу, розташованих у потоці нестисливої рідини, швидкість якої $U$ на нескінченності $€$ залежна від часу лінійна функція координат

$$
U_{i}(t)=U O_{i}(t)+E_{i j}(t) x_{j}
$$

Причому тензор $E_{\mathrm{ij}}$ задовольняє умовам

$$
E_{i j}=0, \quad E_{i j}=E_{j i} \text {. }
$$

Аналітичне рішення задачі про взаємодію двох частинок в ідеальній нестисливій рідині дозволяє провести прямі розрахунки сил FA і FB, діючих на сфери А і В з боку рідини [8]. Сила розраховується як

$$
\begin{aligned}
& F_{i}^{A}=\oint\left(p \delta+\rho\left(U_{i}+u_{i}\right)\left(U_{j}+\right.\right. \\
& \left.+u_{j}\right) n_{j} A d s \text {, }
\end{aligned}
$$

де $\mathrm{p}-$ тиск, u - збурення швидкості, $\rho$ - щільність рідини. Інтеграл береться по поверхні $S^{A}$ частинки A, зовнішня нормаль до якої $€$ вектором nA. Тиск р дорівнює

$$
\mathrm{p}=-\rho \partial \varphi / \partial \mathrm{t}-\rho\left(\mathrm{U}_{\mathrm{j}}+\mathrm{u}_{\mathrm{j}}\right) / 2 .
$$

Отримані вирази для сил FA $\mathrm{i}$ $\mathrm{F}^{\mathrm{B}}$, діючі на частинки $\mathrm{A}$ і В в ідеальній нестисливій рідині дозволяють визначити швидкості руху частинок, набуті ними у результаті взаємодії з потоком 
рідини між собою та прослідити динаміку їх руху. Використовуючи другий закон Ньютона, отримуємо систему диференційних рівнянь. В силу складності виразів для сил, діючих на частинки, система рівнянь вирішувалась кількісно. Нижче на графіках наведені результати розрахунків для випадку, коли щільність частинок менше щільності рідини при положенні орієнтованих уздовж та поперек швидкості потоку рідини, що набігає (рис. 1).

Результати кількісного моделювання показують, що можливо як зближення частинок, так і їх віддалення один від одного. До того ж, якщо швидкість набігаючого потоку нестисливої рідини направлена під кутом, близьким до прямого, відносно лінії, з'єднуючої центри сфер, то частинки зближуються (рис. 1(2)) під дією результату сили Бернуллі. При положенні сфер уздовж швидкості і здійснюється їх віддалення одне від одного.

Розглянемо зараз дві частинки, які розташовані у потоці ідеальної стисливої рідини: $\mathrm{E}_{\mathrm{ii}}=0$, $E_{\mathrm{ij}}=E_{\mathrm{jj}}$.

Розподілення швидкості та тиску навколо частинок описуються рівняннями нестисливої рідини. Проте, якщо характерний розмір $\lambda$ течії, на якій відбувається змінення величин у рідині за рахунок стисливості, задовольняє умові $\lambda>>r$, де $r-$ відстань між частинками, то поблизу частинок рівняння для швидкості і тиску можна записати у вигляді аналогічному для нестислої рідини [8]. Відмінність полягає тільки в умові $\mathrm{E}_{\mathrm{ii}}=0$.

Це легко враховується додатковими доданками у виразі для потенціалу.

Використовуючи вираз для потенціалу швидкості рідини навколо двох частинок в ідеальній стислій рідині, знаходи-

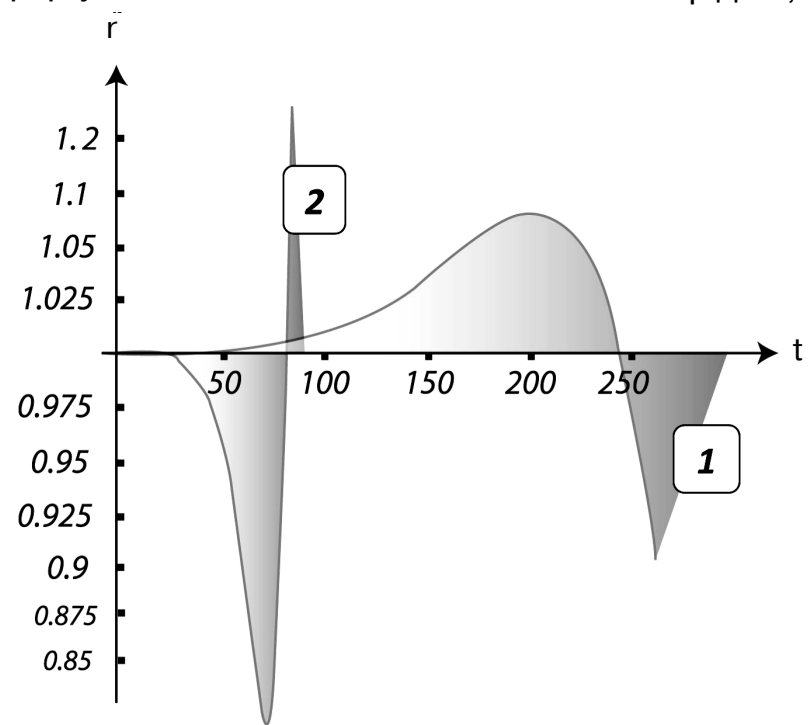

Рис. 1. Результати розрахунків для випадку орієнтації частинок уздовж (1) та поперек (2) потоку 
мо вирази для сил $\mathrm{FA}^{\mathrm{A}} \mathrm{F}^{\mathrm{B}}$, діючих на сфери A і В з боку рідини та складаємо диференційні рівняння руху частинок. Рівняння вирішуються кількісно. Результати розрахунків наведені нижче на графіках для випадку, коли щільність частинок менше щільності рідини і вектор, з'єднуючий центри частинок, орієнтований уздовж або поперек швидкості набігаючого потоку рідини (рис. 2).

Стисливість рідини значно впливає на рух частинок у звуковій хвилі. На відміну від випадку взаємодії частинок в потоці нестисливої рідини об'єднання частинок можливо у випадку, коли вони знаходяться одна за одною відносно напряму розповсюдження хвилі (рис. 2(1)). При розташуванні частинок поперек хвилі відбувається їх віддалення одне від одної (рис. 2(2)).

Результати кількісного моделювання показують, що можли- во як зближення частинок, так і їх віддалення одна від одної. До того ж, якщо швидкість потоку нестисливої рідини, що набігає, направлена під кутом, близьким до прямого, відносно лінії, з'єднуючої центри сфер, то частинки зближуються (рис. 2) під дією результату сили Бернуллі. При положенні сфер уздовж швидкості здійснюється їх віддалення одна від одної [9].

Одержані результати вказують, що механізм коагуляції частинок у звуковій хвилі якісно відрізняється від того, що дає сила Бернуллі у потоці нестисливої рідини.

В реальних умовах при ультразвуковій обробці на швидкість укрупнення та осадження частинок, завислих у рідкому середовищі, впливають інтенсивність та час ультразвукового впливу, а також параметри оброблюваного технологічного об'єму. Для досягнення максимально можливої інтенсивності процесу коагуляції частинок в процесі ульт-

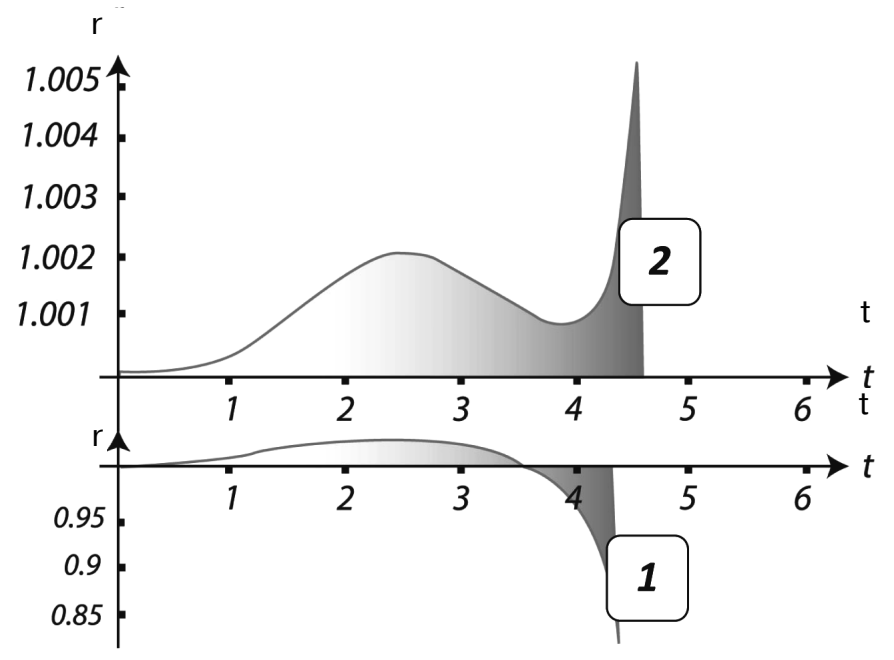

Рис. 2. Результати розрахунків для розташування частинок уздовж (1) та поперек (2) потоку 
развукової обробки металізованого колоїдного розчину необхідно оптимізувати інтенсивність або час ультразвукового впливу.

Поглинута у дефектних зонах кристалічної ґратки стружкових частинок енергія ультразвукової хвилі затрачується на зняття локальних напружень, розблокування дислокацій, збільшення їх рухомості, що забезпечує більш інтенсивний хід очищення металевих пігментів.

Отримані експериментальні результати дозволили провести аналіз процесів, які відбуваються в металізованих колоїдних розчинах при акустичному впливі різної інтенсивності.

\section{Висновки}

Для реалізації процесу інтенсивної коагуляції в малому технологічному об'ємі достатньо 25 \% потужності та часу впливу порядку 2-х хвилин. При збільшенні часу впливу спостерігається невелике погіршення процесу коагуляції, що засвідчує: на малій потужності процес іде більш ефективно, але малий об'єм та більша величина інтенсивності випромінювання у ньому призводять до поступового кавітаційного руйнування збільшених частинок.

Проведені дослідження підтвердили ефективність застосування інтенсивної ультразвукової обробки для прискорення процесу гомогенізації металізованих колоїдних розчинів.

1. Морозов А. С. Стабілізація металізованих колоїдних розчинів поліграфічного призначення / А. С. Морозов // Технологія і техніка друкарства. - 2008. - № 1. - C. 110-117. 2. A. S. Morozov. Metallized printing and bronzing promising technology in printing industry / A. S. Morozov, D. Bezkorovayna, O. Gushcha, E. Sukhina // Четверта міжнародна конференція студентів та аспірантів «До високих технологій на основі новітніх фізико-матеріалознавчих досліджень та комп'ютерного конструювання матеріалів». - Київ, грудень 2009. - С. 35-36. 3. А. С. Морозов. Внутрішні напруження та їх вплив на міцність і структуру фарбової металізованої плівки поліграфічного призначення / А. С. Морозов // Технологія і техніка друкарства. - 2010. - № 1. - С. 179-184. 4. Патент України МПК (2012.01), B41F 11/00, B41M 3/00, C09D 4/00. Спосіб виготовлення захисного металізованого покриття поліграфічного призначення / Морозов А. С., Івасенко М. В., Шаховая О. В., опуб. 25.09.2012. Бюл. № 18. 5. Патент України МПК(2006.01), C09D 11/20. Металізована фарбова плівка / Морозов А. C., опуб. 26.03.2012. Бюл. № 6. 6. Bernal I. D. Geometrical approach to the structure of liquids / I. D. Bernal // J. Appl. Phys. Lett. - 2000. - Vol. 44, № 9. - Р. 874-876. 7. А. с. № 154036 СССР. Способ очистки материалов. Райченко А. И., Морозов А. С., Ивлиев А. И. и др. 8. Исследование процесса коагуляции частиц бурового раствора [Електронний ресурс.] - Режим доступу : URL htpp://zhurnal. relarn.ru/articles/2010//041.pdf. 9. В. Л. Галяс. Фізична і колоїдна хімія / В. Л. Галяс, А. Г. Колотницький. - Львів : Стрийська міська друкарня. - 2004. - 272 с.

1. Morozov A. S. Stabilizatsiia metalizovanykh koloidnykh rozchyniv polihrafichnoho pryznachennia / A. S. Morozov // Tekhnolohiia i tekhnika drukarstva. 2008. - № 1. - S. 110-117. 2. A. S. Morozov. Metallized printing and bronzing promising technology in printing industry / A. S. Morozov, D. Bezkorovayna, 
O. Gushcha, E. Sukhina // Chetverta mizhnarodna konferentsiia studentiv ta aspirantiv «Do vysokykh tekhnolohii na osnovi novitnikh fizyko-materialoznavchykh doslidzhen ta komp'iuternoho konstruiuvannia materialiv». - Kyiv, hruden 2009. - S. 35-36. 3. A. S. Morozov. Vnutrishni napruzhennia ta yikh vplyv na mitsnist i strukturu farbovoi metalizovanoi plivky polihrafichnoho pryznachennia / A. S. Morozov // Tekhnolohiia i tekhnika drukarstva. - 2010. № 1. - S. 179-184. 4. Patent Ukrainy MPK (2012.01), V41F 11/00, V41M 3/00, S09D 4/00. Sposib vyhotovlennia zakhysnoho metalizovanoho pokryttia polihrafichnoho pryznachennia / Morozov A. S., Ivasenko M. V., Shakhovaia O. V., opub. 25.09.2012. Biul. № 18. 5. Patent Ukrainy MPK(2006.01), S09D 11/20. Metalizovana farbova plivka / Morozov A. S., opub. 26.03.2012. Biul. № 6. 6. Bernal I. D. Geometrical approach to the structure of liquids / I. D. Bernal // J. Appl. Phys. Lett. - 2000. - Vol. 44, № 9. - P. 874-876. 7. A. s. № 154036 SSSR. Sposob ochistki materialov. Rajchenko A. I., Morozov A. S., Ivliev A. I. i dr. 8. Issledovanie processa koaguljacii chastic burovogo rastvora [Elektronnyi resurs.] - Rezhym dostupu : URL htpp://zhurnal. relarn.ru/articles/2010//041.pdf. 9. V. L. Halias. Fizychna i koloidna khimiia / V. L. Halias, A. H. Kolotnytskyi. - Lviv : Stryiska miska drukarnia. - 2004. - 272 s.

Рецензент - Т. А. Роїк, д.т.н., професор, НТУУ «КПІ»

Надійшла до редакції 02.04.13 